\title{
АНТИТРОМБОЦИТАРНАЯ ТЕРАПИЯ
}

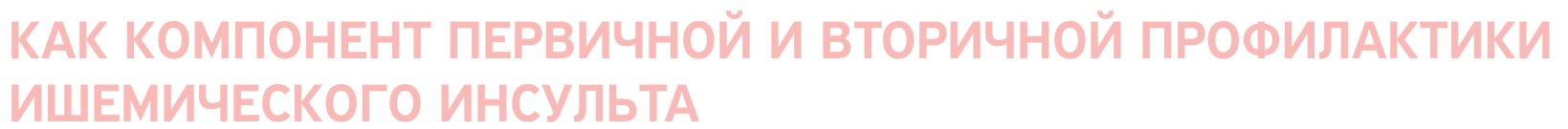

\begin{abstract}
Применение антиагрегантных препаратов является важным звеном первичной и вторичной профилактики инсультов. Все существующие в настоящее время антиагреганты являются антагонистами агрегации тромбоцитов в различных точках приложения, но различаются по механизму действия. Успешность лечения и профилактики сосудистых заболеваний мозга антиагрегантными препаратами во многом зависит от чувствительности, восприимчивости самих тромбоцитов к этому воздействию. Изучение изменения функциональной активности тромбоцитов при лечении антиагрегантами позволяет контролировать эффективность проводимой терапии, выявлять резистентность и сниженную реактивность к препарату, подбирать лекарственное средство и его дозировку. В практическом плане такой подход дает возможность оценить индивидуальный ответ пациента на антитромбоцитарную терапию, подобрать эффективный антитромбоцитарный препарат, снизить риск отдаленных осложнений, повторных инсультов и, следовательно, улучшить качество жизни и прогноз заболевания.
\end{abstract}

Ключевые слова: тромбоциты, эндотелий, сосуды, дипиридамол, окисление, воспаление, гемостаз.

E.Y. SOLOVYOVA, MD, PhD in Medicine, E.D. DZHUTOVA, PhD in medicine, E.A. TYUTYUMOVA

Russian National Research Medical University named after N.I. Pirogov, Moscow

ANTIPLATELET THERAPY AS AN ELEMENT OF PRIMARY AND SECONDARY PREVENTION OF ISCHEMIC STROKE

Antiplatelet medications are essential in the primary and secondary prevention of stroke. All currently available antiplatelet drugs are platelet aggregation inhibitors acting at various points of application, but they differ in their mechanism of action. Successful treatment and prevention of cerebrovascular diseases with antiplatelet drugs largely depend on the sensitivity and susceptibility of platelets to the impact produced by these medications. Study of changes in platelet functional activity during treatment with antiplatelet drugs allows to monitor the effectiveness of therapy, identify resistance and detect lower reactivity to the drug, as well as to select the proper drug and its dosage. In practice, the approach helps to assess the individual patient response to antiplatelet therapy, choose the effective antiplatelet medication, reduce the risk of long-term complications and recurrent stroke, and, therefore, improve the quality of life and prognosis of the disease.

Keywords: platelets, endothelium, blood vessels, dipyridamole, oxidation, inflammation, hemostasis.

\section{ВВЕДЕНИЕ}

Острые нарушения мозгового кровообращения (ОНМК) по сей день остаются важнейшей медико-социальной проблемой во всех экономически развитых странах мира, занимая лидирующие позиции по заболеваемости и смертности во всем мире. Заболеваемость ОНМК составляет 2,5-3 случая на 1 тыс. населения в год, а смертность в остром периоде ОНМК в России достигает 35\%, увеличиваясь на 12-15\% к концу первого года, в течение 5 лет после инсульта умирают 44\% пациентов. Наиболее высокая смертность регистрируется при обширных инсультах в каротидном бассейне (60\% в течение первого года). Наряду с высокой смертностью, нарушения мозгового кровообращения являются ведущей причиной инвалидизации у взрослых. Постинсультная инвалидизация занимает 1-е место среди всех причин инвалидности и составляет 3,2 на 10 тыс. населения. К труду возвращаются лишь 20\% лиц, перенесших ОНМК, при том что 1/3 заболевших - люди трудоспособного возраста. Всего в России ОНМК ежегодно развиваются у 400-450 тыс. человек, примерно 200 тыс. из них погибают. В стране проживают более 1 млн человек, перенесших ОНМК, причем 80\% из них являются инвалидами [4].
Исследования о значимости систем гемореологии и гемостаза в ангионеврологии свидетельствуют о том, что у всех больных с ишемическими сосудистыми заболеваниями мозга, включая и самые ранние их формы, имеют место однонаправленные изменения этих систем. Признается, что одним из центральных звеньев патофизиологии ишемического цереброваскулярного эпизода, независимо от причин и механизмов его развития, является усиление гемостатической активации с изменением реологических свойств крови и эндотелиальная дисфункция, иногда вплоть до развития тромбоза или эмболии, приводящих к нарушению мозгового кровообращения.

Наиболее частой причиной тромбоокклюзирующего поражения сосудистой системы мозга является атеротромбоз, причем атеротромбоз и его тромбоэмболические осложнения являются непосредственной причиной более 60\% ишемических нарушений мозгового кровообращения (НМК) [13].

Атеротромбоз - генерализованный и постоянно прогрессирующий процесс, зависящий от эволюции атеросклеротических изменений в сосудах. Процесс формирования атеротромботического поражения сосуда сложен, многокомпонентен и зачастую очень длителен. Атеротромбоз магистральных артерий головы, так же как и ате- 
ротромбоз в других сосудистых бассейнах, начинается с дестабилизации атеросклеротической бляшки, которая за счет пристеночного тромбообразования может увеличиваться в объеме вплоть до полной закупорки просвета артерии. Кроме того, свежие атеротромботические массы при условии сохранности фибринолитического потенциала сосудистой стенки и крови способны подвергаться полному лизису либо фрагментации. В последнем случае формируется тромбоэмбол, устремляющийся с током крови в более мелкие дистальные артерии. Таким образом, исходом атеросклеротического поражения сосудистой системы мозга может быть развитие ишемических НМК. Вместе с тем достаточно долго - годы, а порой и десятилетия - процесс может быть клинически асимптомным.

\section{Одним из центральных звеньев патофизиологии ишемического череброваскулярного эпизода, независимо от причин и механизмов его развития, является усиление гемостатической активации с изменением реологических свойств крови, иногда вплоть до развития тромбоза или эмболии}

Клиническая манифестация большинства сердечно-сосудистых катастроф непосредственно связана с моментом нарушения целостности атеросклеротической бляшки [14].

Больной, перенесший атеротромботический эпизод, имеет повышенный риск повторного события в том же или другом сосудистом бассейне [6]. Так, комбинированный риск возникновения ишемического инсульта, инфаркта миокарда или смерти от сосудистой причины у пациентов с атеротромботическим поражением двух сосудистых бассейнов на 25\% выше, а при вовлечении трех сосудистых бассейнов, соответственно, на 51\% выше по сравнению с поражением единственного сосудистого бассейна [25]. Количество повторных инсультов составляет около 25\% от общего количества церебральных инсультов [6]. Вероятность повторного инсульта увеличивается более чем в 10 раз у пациентов, перенесших инсульт или транзиторную ишемическую атаку, поэтому вторичная профилактика особенно важна. Согласно доказательной базе многоцентровых клинических исследований антиагрегантная терапия является эффективной для предотвращения инсульта [13].

Важным этапом для внедрения антитромботической терапии в клиническую ангионеврологию была расшифровка ключевой роли кровяных пластинок в процессах тромбообразования, а также определение значимости тромбоцитарных дисфункций и нарушений тромбоцитарно-сосудистого гемостаза в патогенезе ишемических нарушений мозгового кровообращения.

\section{СОСУДИСТО-ТРОМБОЦИТАРНЫЙ ГЕМОСТАЗ ПРИ ИШЕМИИ МОЗГА}

Основной задачей гемостаза является сохранение жидкого состояния циркулирующей и депонированной крови в кровеносном русле, а также остановка кровотечения и предотвращение кровопотери при повреждении кровеносных сосудов. Органы и ткани, участвующие в выполнении этих функций, образуют систему гемостаза. Элементы системы гемостаза участвуют в воспалении, репарации тканей, поддержании гомеостаза [5]. Условно систему гемостаза можно разделить на два звена: сосудисто-тромбоцитарный (первичный) и коагуляционный (вторичный). Составляющие механизмы первичного гемостаза обеспечивают остановку кровотечения за счет спазма сосуда и образования тромбоцитарного агрегата (тромбоцитарной или первичной пробки) в зоне повреждения сосуда. В физиологических условиях неповрежденная сосудистая стенка способствует поддержанию жидкого состояния крови. Внутренний слой сосудов представлен эндотелиальными клетками, клеточная мембрана которых обладает высокой текучестью, что является важным условием антитромбогенных свойств сосудистой стенки, поскольку она функционирует как целостный пласт и исключает контакт прокоагулянтов плазмы крови с субэндотелиальными структурами. Эндотелий содержит на своей поверхности и выделяет в кровоток вещества, которые препятствуют свертыванию, такие как, например, специфический мембранный белок - тромбомодулин, который с высокой аффинностью связывает тромбин, образуя тромбин-тромбомодулиновый комплекс, активирующий протеин С. Это свойство предотвращает образование тромба на интактном эндотелии и ограничивает рост тромба за пределы повреждения. При повреждении или воспалении стенка сосуда принимает участие в образовании тромба. Субэндотелиальные структуры, контактирующие с кровью только при повреждении или развитии патологического процесса, обладают мощным тромбогенным потенциалом. В зоне повреждения происходит активация эндотелия, в результате чего у него появляются прокоагулянтные свойства [5].

\section{ЛЕЙКОЦИТАРНО-ТРОМБОЦИТАРНЫЕ ВЗАИМОДЕЙСТВИЯ ПРИ АТЕРОТРОМБОЗЕ}

Более 130 лет назад G. Bizzozero высказал предположение о той существенной роли, которую играют лейкоциты и тромбоциты в механизме тромбобразования.

К сожалению, только на протяжении последних 25 лет исследователи подвергли тщательному изучению процесс взаимодействия тромбоцитов с лейкоцитарными клетками [5]. В работах Egbrink M.G. et al. было установлено, что особенно тесная связь между тромбоцитами и лейкоцитами осуществляется в зоне повреждения сосудистой стенки [30]. При этом было отмечено, что в ходе исследований, проведенных на условно здоровой группе с использованием сканирующей электронной микроскопии, не было обнаружено признаков тромбоцитарно-лейкоцитарной адгезии в венозной крови по сравнению с 28,6\% больных ИБС [3]. Лейкоциты больных ИБС адгезировали от 1 до 6 тромбоцитов [3]. В работе Б.И. Кузник показано, что при различных воспалительных процессах до 50\% присутствующих в кровотоке лейкоцитов присоединяют к своей поверхности тромбоциты [5]. Однако следует отметить, что при развитии воспалительного про- 
цесса стремительно развивается способность тромбоцитов к спонтанной агрегации, при этом в кровотоке может значительно возрастать количество агрегатов, образованных тромбоцитами и лейкоцитами. В острой стадии с одним лейкоцитом взаимодействует более 5 тромбоцитов, а количество лейкоцитов, контактирующих с тромбоцитами, превышает 50\% от их общего числа [33]. При определенных условиях (присоединение инфекционных и аутоиммунных заболеваний) лейкоциты, в т. ч. нейтрофилы и моноциты, не только присоединяют к себе тромбоциты, но и осуществляют их фагоцитоз [5]. Особенно интенсивно лейкоциты связываются с тромбоцитами, которые «прикреплены» к сосудистой стенке. Создание условий для прикрепления лейкоцитов к тромбоцитам осуществляется благодаря экспрессии на поверхности кровяных пластинок Р-селектина, Gplba, JAM-3, ICAM-3 и других рецепторов [57]. При этом осуществляется связывание Р-селектина с PSGL-1, Gplba c MAC-1, фибриногена c Gpllb/IIla и кининогена с Gplba [50].

\section{Атеротромбоз и его тромбоэмболические осложнения являются непосредственной причиной более $60 \%$ ишемических нарушений мозгового кровообращения}

Были получены достоверные доказательства, указывающие на то, что взаимодействие с лейкоцитами осуществляют главным образом дискоциты, протромбоциты не участвуют в образовании лейкоцитарно-тромбоцитарных агрегатов [2]. При взаимодействии тромбоцитов с лейкоцитами происходит образование тромбоцитарных и лейкоцитарных микровезикул, что сопровождается развитием гиперкоагуляции. Тромбоцитарные микровезикулы («тромбоцитарная пыль») несут на своей поверхности различные адгезивные молекулы, в т. ч. и Р-селектин. В кровеносном русле данный вид межклеточного контакта вызывает агрегацию лейкоцитов и их прилипание к адгезивной поверхности. Однако взаимодействие активированных и нестимулированных нейтрофилов с тромбоцитами существенно отличается. Так, неактивированные нейтрофилы подавляют стимуляцию тромбоцитов в присутствии коллагена и тромбина [45]. Данное взаимодействие между этими клетками осуществляется в условиях тесного межклеточного контакта, при котором не требуется экспрессия Р-селектина на поверхности кровяных пластинок. В присутствии же моноклональных антител к Р-селектину происходит усиление ингибирующего эффекта неактивированными нейтрофилами. Вполне возможно, что антиагрегирующее действие нейтрофилов связано с влиянием эластазы, поскольку добавление ее ингибитора приводило к исчезновению этого эффекта [41]. Способностью прикрепляться к поверхности нейтрофилов обладает всего лишь 2,5\% гранулоцитов, при этом к одному нейтрофилу прикрепляется от 1 до 4 тромбоцитов, но если их активировать добавлением АДФ, их способность прилипать к нейтрофилам возрастает в несколько раз. Все это происходит за счет взаимодействия высвобождаемого из а-гранул и экспрессируемого на мембране тромбоцитов Р-селектина c L-селектином на клеточной поверхности нейтрофилов, но в условиях кровотока такой контакт подвержен разрыву [27, 51]. Следует заметить, что при активации тромбоцитов и лейкоцитов выделяемый ими NO полностью ингибирует синтез мощного агрегирующего агента тромбоцитов - PAF. При этом в условиях циркуляции происходит прикрепление тромбоцитов к поврежденному эндотелию, а движущиеся в потоке крови нейтрофилы совершают «роллинг» по их поверхности [49]. В результате активации нейтрофилов различными хемокинами «роллинг» способствует образованию прочной связи с мембраной тромбоцитов. Данное взаимодействие осуществляется за счет взаимодействия специфических рецепторов нейтрофилов, таких как $\beta_{2}$-интегрин Мас-1 (CD11b/CD38), LFA-1(CD11a/CD18), с рецепторами тромбоцитов ICAМ-2, CD62 (Р-селектин), CD15 [28, 56]. Образование связующего моста между тромбоцитом и нейтрофилом осуществляется за счет связывания фибриногена с рецептором тромбоцита Gpllb/llla (CD41a), TF, фактором Ха [18]. При этом значительно сильнее эта реакция происходит при наличии окисленного фибриногена. Активированные тромбоциты выделяют также потенциальные агонисты, стимулирующие нейтрофилы, такие как PAF, аденин-нуклеотиды, различные хемокины и фактор активации нейтрофилов-2 (NAF-2), некоторые из них участвуют в $\beta_{2}$-интегрин-зависимом взаимодействии лейкоцитов с поверхностью тромбоцитов [5]. Таким образом, можно заключить, что наличие дублирующих механизмов адгезии обеспечивает надежное образование связи нейтрофилов и тромбоцитов (рис. 1).

\section{РОЛЬ ОКИСЛИТЕЛЬНОГО СТРЕССА И ЛИПОПРОТЕИНОВ ПРИ АТЕРОТРОМБОЗЕ}

Одним из значительных факторов, способствующих развитию атеротромбоза, является окислительный стресс. Известно, что поврежденный эндотелий сосудистой стенки продуцирует активные формы кислорода (АФК), а также активированные лейкоциты и тромбоциты. Развивающаяся агрегация тромбоцитов за счет образования тромбоциттромбоцитарных взаимодействий связана с увеличением потребления кислорода [23] и заметному увеличению глутатион-дисульфида [24]. Образующиеся активированные тромбоцитарно-нейтрофильные комплексы высвобождают $\mathrm{NO}$, который взаимодействует с супероксид-анион-радикалом, модулируя, таким образом, воспалительный процесс в сосудистой стенке. При этом происходит стимуляция НАДФоксидазы нейтрофилов и тромбоцитарной изоформы НАДФ-оксидазы, что способствует развитию кислородного взрыва [36]. Выделение АДФ во внеклеточную среду увеличивает стимулированную агонистами кислородную реакцию в нейтрофилах. Образующийся оксид азота ингибирует активацию тромбоцитов [26] и предотвращает развитие тромбоза [54]. В одной из зарубежных работ, где изучалось применение экзогенного NO, происходило ингибирование на поверхности тромбоцитов поверхностных гликопротеинов, в т. ч. Р-селектина и интегрина (гликопротеина Ilb/lla) 
[43]. Вместе с тем оксид азота снижает окисление ЛПнП, однако холестерол окисленных ЛПНП увеличивает синтез кавеолина-1, который инактивирует NO-синтазу, ингибируя синтез оксида азота [59]. Сами ЛПНП являются индукторами, вызывающими экспрессию адгезивных молекул и HSP60 на эндотелиальных клетках [17].

\section{РОЛЬ С-РЕАКТИВНОГО БЕЛКА ПРИ АТЕРОТРОМБОЗЕ}

Известно, что C-реактивный белок (CRP) представляет собой комплекс соединений, обладающих различными свойствами. Среди них выделяется нео-CRP (MCRP), который состоит из мономеров и содержит антигенные детерминанты, не присутствующие в нативном белке; мCRP активирует продукцию супероксид-анион радикала в фагоцитах, увеличивает синтез эндотелиина-1, воспалительных цитокинов IL-1a и $\beta$, IL-6 и TNFa. Помимо этого,
нео-CRP инициирует экспрессию адгезивных молекул sICAM-1, sVCAM-1, Е-селектин (при этом происходит снижение синтеза провоспалительного цитокина IL-10), экспрессию TF моноцитами и макрофагами, в результате чего происходит усиление течения гемокоагуляции и снижается активность TFPI, при этом усиливается апоптоз эндотелиоцитов [53]. Следует упомянуть о влиянии мCRP на функциональные свойства тромбоцитов, который вызывает секрецию а-гранул серотонина и образование тромбоксана $\mathrm{A}_{2}$, уменьшает синтез NO, тем самым вызывая необратимую агрегацию тромбоцитов и их адгезию к эндотелию аорты. В одной из работ было достоверно доказано, что при инкубации эндотелиальных клеток пупочного канатика человека с 20 мг/л CRP происходит увеличение CD31-, CD51-позитивно окрашенных везикул, содержащих TF, при этом синтез NO снижается [57]. Приведенные выше данные показывают, насколько сложен механизм развития атеротромбоза.

Рисунок 1. Взаимодействия: тромбоцит-тромбоцитарные и тромбоцит-лейкоцитарные, а также с поврежденным активированным в процессе воспаления эндотелием

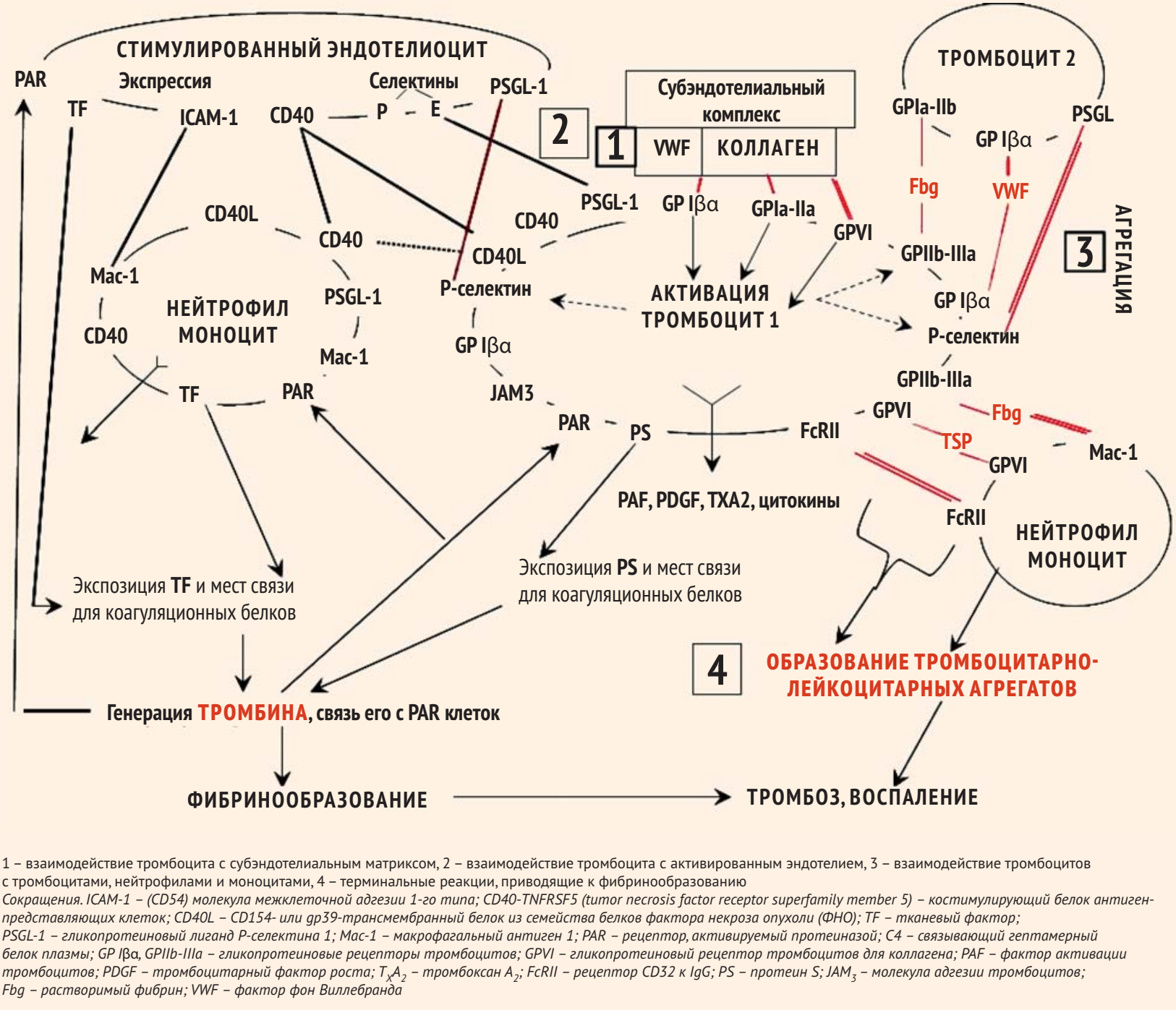




\section{АНТИТРОМБОЦИТАРНЫЕ ПРЕПАРАТЫ}

В связи с активным участием тромбоцитов в процессах тромбообразования, многогранностью их функциональной активности с вовлечением большого количества биологически активных веществ, единым конечным этапом формирования тромба, возможно активное вмешательство с лечебной целью на различных стадиях патологического процесса для прерывания этой цепи. Представленные на сегодняшний день антиагрегантные препараты различаются по своим основным механизмам, но все они являются антагонистами агрегации тромбоцитов в различных точках приложения [13].

По основному механизму действия антитромбоцитарные препараты можно разделить на следующие группы (puc. 2).

\section{1. Ингибиторы циклооксигеназы (ЦОГ) - ацетилсалициловая кислота (аспирин).}

Аспирин необратимо ингибирует циклооксигеназу (ЦОГ) тромбоцитов, вследствие чего уменьшается синтез тромбоксана А2 - индуктора агрегации тромбоцитов и вазоконстриктора. Циклооксигеназа имеет 2 изоформы (ЦОГ-1 и ЦОГ-2), аспирин блокирует обе изоформы, однако его активность в отношении ЦОГ-1 в тромбоцитах в 50-100 раз выше, чем влияние на ЦОГ-2 в моноцитах и других клетках воспаления. Угнетение ЦОГ приводит к уменьшению образования циклических эндоперекисей, из которых в дальнейшем образуются не только тромбоксан, но и простациклин - важнейший антиагрегант и вазодилататор. Блокада тромбоксана осуществляется преимущественно вследствие воздействия аспирина на

\section{Рисунок 2. Классификация антитромботических средств}

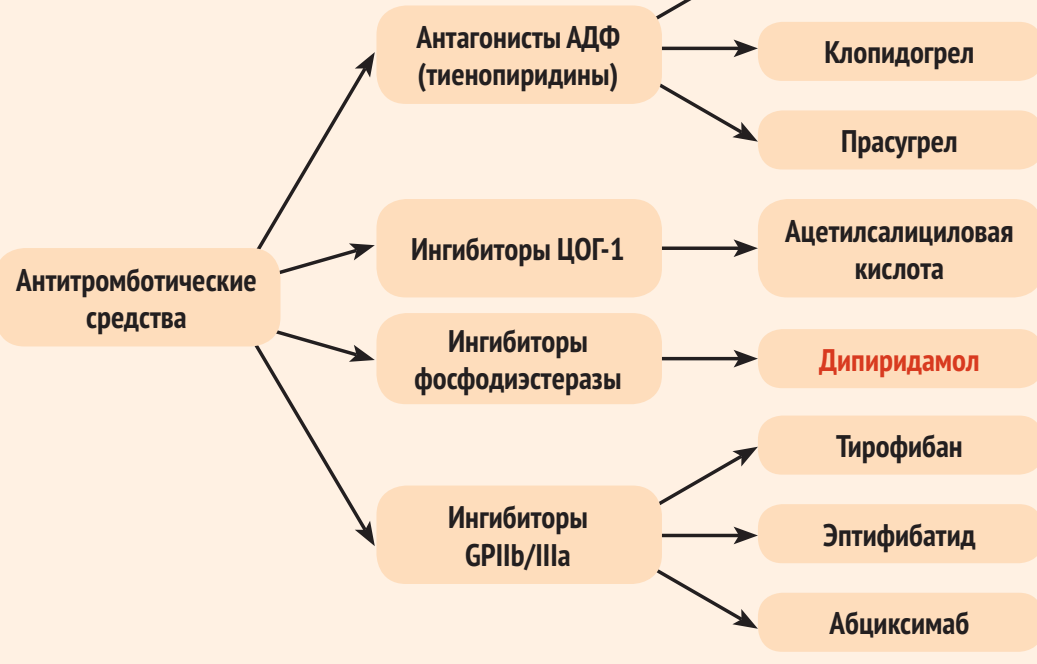

Антиагреганты классифицированы в соответствии с механизмом действия.

Классы лекарственных соединений включают: антагонисты АДФ (тиенопиридины), ингибиторы ЦОГ-1

(единственным представителем этого класса является ацетилсалициловая кислота), ингибиторы фосфодиэстеразы и антагонисты GPIIb/IIIa.
ЦОГ-1 в тромбоцитах, в то время как эффекты аспирина на образование простациклина осуществляются за счет ЦОГ-1 и ЦОГ-2. При использовании низких доз (75-150 мг) действие аспирина оптимально: при достаточной блокаде синтеза тромбоксана в наименьшей степени угнетается синтез простациклина [7].

В последние годы был выявлен феномен, получивший название «аспиринорезистентность», подразумевающий отсутствие снижения синтеза тромбоксана при терапии аспирином [31].

Причины снижения эффективности АСК многообразны, среди них чаще всего отмечают следующие: генетические особенности (генетический полиморфизм), прием НПВП, конкурирующих с АСК за ЦОГ-1-рецепторы, недостаточная абсорбция кишечнорастворимой формы АСК, неадекватная дозировка [1].

При этом распространенность резистентности к аспирину составляет от 5 до 40\% и в значительной степени зависит от используемых методов оценки и изучаемой популяции [20, 48].

До 75\% сосудистых событий возникают на фоне продолжающейся аспиринотерапии, что приводит к необходимости расширения поиска других антитромбоцитарных препаратов.

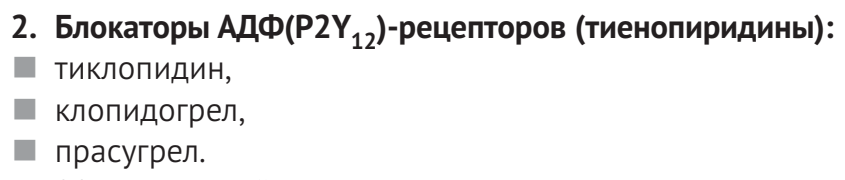

Механизм действия тиенопиридинов связан с селективным ингибированием АДФ-индуцируемой агрегации тромбоцитов. Тромбоциты имеют 3 вида рецепторов к АДФ: регулируемый лигандами ионный канал $\mathrm{P} 2 \mathrm{X}_{1}$, связанный с G-белком рецептор $\mathrm{P}_{2} \mathrm{Y}_{1}$ и изученный в меньшей степени рецептор P2Y 12 . Тиенопиридины необратимо модифицируют Р2Y 12 -рецептор, что в свою очередь приводит к ингибированию стимуляции аденилатциклазного механизма и блокированию связанного с ним сигнала, направленного на усиление агрегации тромбоцитов. Начало действия тиенопиридинов отсрочено, и связано это с необходимостью их превращения в печени в активные метаболиты, которые и осуществляют воздействие на тромбоциты [7].

Тиклопидин обладает дозозависимым антиагрегационным действием. Доказана его высокая эффективность в предотвращении инсульта (CATS, 1989) у пациентов, перенесших нарушение мозгового кровообращения: установлено, что ежедневный прием тиклопидина в дозе 500 мг по сравнению с плацебо на 
30\% снижает вероятность повторения инсульта или возникновения сосудистой смерти и на 21\% снижает риск возникновения инсульта. В исследовании TASS при сравнении с аспирином (в дозе 1300 мг/сут) показано преобладание тиклопидина (500 мг/сут) в отношении уменьшения частоты ишемических эпизодов у больных с ТИА и малыми инсультами [13].

Применение тиклопидина ограничивается его побочными эффектами, среди которых возможность развития гиперхолестеринемии, нейтропении. На фоне терапии тиклопидином описаны случаи тромбоцитопении, анемии и тромбоцитопенической пурпуры [7].

\section{Вероятность повторного инсульта} увеличивается более чем в 10 раз у пациентов, перенесиих инсульт или транзиторную ишемическую атаку, поэтому вторичная профилактика особенно важна

Клопидогрел, являющийся ацетилированным производным тиклопидина, имеет лучший профиль безопасности и в 6 раз превышает антиагрегантное действие последнего. Помимо своего основного механизма воздействия на агрегацию тромбоцитов, клопидогрел может также ингибировать агрегацию, вызванную другими индукторами, через влияние на содержание внутриклеточного АДФ, необходимого для активации IIb/IIla гликопротеиновых рецепторов тромбоцитов. Клиническая эффективность клопидогрела для вторичной профилактики наиболее полно была продемонстрирована в многоцентровом исследовании CAPRIE (1996), где клопидогрел сравнивался с аспирином и показал большую эффективность в отношении снижения частоты сердечно-сосудистых эпизодов у больных высокого риска (недавно перенесших инфаркт миокарда, инсульт и страдающих перемежающейся хромотой) $[7,13]$.

К недостаткам клопидогрела можно отнести значительные межиндивидуальные различия показателей агрегации тромбоцитов после приема стандартной дозы (75 мг) препарата, а также относительно медленную скорость достижения эффекта (несколько дней). Для ускорения эффекта используют нагрузочные дозы (300 мг). Потенциальный механизм вариабельного ответа на клопидогрел включает неполноту абсорбции, лекарственные взаимодействия, генетический полиморфизм ферментов цитохромов СYР, рецепторов Р2Y 12 , АДФ-рецепторов, рецепторов Ilb/IIIa. Частота резистентности варьирует и может достигать 25\% [12].

Прасугрел - представитель третьего поколения тиенопиридинов. Его активность не зависит от генетического полиморфизма, и он оказывает более мощный, быстрый и стойкий эффект по сравнению с клопидогрелом. Это подтвердилось и клинически - в исследовании TRITON-TIMI 38 у пациентов с острым коронарным синдромом, которым проводилась чрескожная ангиопластика, прасугрел был более эффективен в плане профилактики инфаркта миокарда, чем клопидогрел, однако результаты оценки безопасности оказались не в пользу прасугрела, что было связано с большей частотой геморрагических осложнений, в особенности у пациентов, перенесших инсульт или ТИА. Прасугрел не был разрешен для вторичной профилактики инсульта [10].

\section{3. Блокаторы GP Ilb/IIla-рецепторов:}

- моноклональные антитела: абциксимаб, монафрам,

- циклические пептиды: эптифибатид,

- непептидные блокаторы: тирофибан, орбофибан, ксемилофибан, ламифибан, сибрафибан.

Конечным общим этапом агрегации тромбоцитов является активация тромбоцитарных гликопротеиновых (ГП) Ilb/IIla-рецепторов с их последующим связыванием циркулирующими молекулами фибриногена. В связи с этим блокаторы Ilb/IIla-рецепторов тромбоцитов, которые способны полностью подавлять агрегацию тромбоцитов, индуцированную любым индуктором, теоретически представляются наиболее эффективными среди прочих антиагрегантов [13].

Созданные ингибиторы этого рецептора неоднородны по своей природе и фармакологическим свойствам. Различают препараты, созданные на основе моноклональных антител к данному рецептору (в качестве лекарственных препаратов используют фрагменты антител), а также синтетические субстанции, имеющие пептидную или непептидную (пептидомиметики) структуру, сходную с аминокислотной последовательностью (Arg-Gly-Asp, Аргинин - Глицин - Аспарагин), называемой RGD.

Препараты - производные антител, такие как абциксимаб, взаимодействуя с ГП Ilb/IIla, фактически делают недоступным определенный участок связывания фибриногена. Образуя прочный комплекс с ГП IIb/IIla, они могут достаточно долго циркулировать в кровотоке в связанном с тромбоцитами состоянии. Именно поэтому после прекращения их введения агрегационная активность тромбоцитов остается сниженной еще в течение нескольких дней, несмотря на быстрое, в течение 10-12 ч, выведение из плазмы свободных (не связанных с тромбоцитами) молекул антител [9]. Однако назначенный профилактически перед каротидным стентированием абциксимаб не уменьшает церебральных ишемических осложнений. Лишь сочетание базисной антиагрегантной терапии (аспирин и тиенопиридины) и абциксимаба перед этим вмешательством способствовало уменьшению постоперационных побочных эффектов.

RGD-подобные блокаторы ГП IIb/IIIa, такие как пептид эптифибатид (интегрилин) и пептидомиметик тирофибан, являются конкурентными ингибиторами связывания фибриногена. Интегрилин обладает чрезвычайно малым периодом полужизни и в связи с этим коротким антитромбоцитарным эффектом [13].

Была доказана эффективность внутривенных ингибиторов GP IIb/IIla у пациентов с острой коронарной недостаточностью. Клинические испытания пероральных препаратов показали, что по эффективности они не превосходили аспирин, а по риску кровотечений и токсичности существенно превосходили его [10]. 


\section{4. Блокаторы фосфодиэстеразы (ФДЭ) и потенциаторы аденозина - дипиридамол.}

Дипиридамол представляет собой производное пиримидо-пиримидина. В настоящее время установлено двоякое действие на атеротромботические процессы посредством влияния как на тромбоциты, так и на сосудистую стенку [32]. Помимо основного механизма действия, снижающего агрегацию тромбоцитов за счет повышения уровня цАМФ, этот препарат воздействует также на систему АДФ, тромбина, арахидоновой кислоты. Дипиридамол препятствует захвату аденозина эритроцитами, увеличивая, таким образом, плазменную концентрацию аденозина и стимулируя активность тромбоцитарной аденилатциклазы. Кроме того, дипиридамол подавляет фосфодиэстеразу циклических АМФ и ГМФ, способствуя их накоплению, что усиливает сосудисторасширяющий эффект оксида азота и простациклина. Отмечено также влияние дипиридамола на эритроциты [46], улучшение микроциркуляции за счет увеличения их деформируемости. Дипиридамол оказывает антиоксидантный эффект, а также подавляет пролиферацию гладкомышечных клеток сосудистой стенки, способствуя торможению развития атеросклеротических бляшек и рестеноза [13].

\section{МЕХАНИЗМ ДЕЙСТВИЯ ДИПИРИДАМОЛА}

В результате проведенных исследований было установлено, что добавление дипиридамола способствовало увеличению внеклеточного уровня аденозина путем ингибирования поглощения аденозина эритроцитами, что приводило к ингибированию агрегации тромбоцитов (рис. 3a) [19]. Аденозин высвобождался из клеток сосудов стенки и тромбоцитов во внеклеточное про- странство в качестве продукта распада аденозинтрифосфата (АТФ). Освобожденные адениннуклеотиды стремительно трансформировались в аденозин под действием нуклеаз. В циркулирующей крови свободный аденозин быстро удаляется из плазмы крови при помощи специфического носителя аденозина в эритроцитах. В клинически значимых дозах дипиридамол ингибирует поглощение аденозина эритроцитами более чем на $90 \%$ и увеличивает плазменные уровни аденозина на 60\% $[29,35]$. В ходе исследований было показано, что аденозин, воздействуя через рецепторы аденозина, стимулирует аденилатциклазу в тромбоцитах и повышает уровень внутриклеточного циклического аденозинмонофосфата (цАМФ), который является мощным ингибитором активации тромбоцитов [22]. Следует отметить, что введение дипиридамола в среду, содержащую тромбоциты, способствовало увеличению внутриклеточного уровня цАМФ в этих клетках путем предотвращения распада цАМФ в результате ингибирования фосфодиэстеразы (ФДЭ) [44, 55, 60]. Также было показано, что дипиридамол ингибирует агрегацию тромбоцитов в цельной крови в условиях in vitro и потенцирует антиагрегантное действие аденозина [37, 38].

ДП ингибирует циклический гуанин монофосфат (цГМФ), ФДЭ (фосфодиэстеразу), усиливает цГМФзависимое сосудорасширяющее воздействие на гладкие мышцы (рис. 3) [52]. К тому же активирует синтез простациклина (PGI 2), который является не только мощным ингибитором агрегации тромбоцитов, но и оказывает сосудорасширяющее действие за счет увеличения уровня внутриклеточной цАМФ [21], а также потенцирует вазодилатацию за счет увеличения локальных уровней аденозина [19].

Таким образом, как показали исследования, дипиридамол оказывает прямое и косвенное сосудорасширяющее действие на гладкие мышцы сосудов. Происходит потенцирование NO/цГМФ сосудорасширяющего действия и снижения агрегации тромбоцитов за счет ингибирования цГМФ и ФДЭ $[15,40]$, что способствует увеличению перфузии миокарда при сердечной недостаточности и стабилизации протекания ишемической болезни сердца, [42, 39, 61], а также снижению тяжести ишемического инсульта через NO- и аденозин-опосредованное воздействие [34].

Многочисленные клинические исследования показали эффективность дипиридамола, обладающего рядом преимуществ перед ацетилсалициловой кислотой (АСК): антиагрегантное действие не сопровождается подавлением активности циклооксигеназы и уменьшением синтеза про- 
стациклина, отсутствует повреждающее действие на слизистые оболочки, существует возможность растворения в среде пониженной кислотности (наблюдаемой обычно у пожилых лиц или у лиц, принимающих антациды), а также возможность управляемого антитромботического эффекта путем подбора оптимальных доз [13].

Применение в качестве антиагреганта дипиридамола (Курантил ${ }^{\circledR}$ №75, Berlin-Chemie, Германия) в средних дозах (225 мг/сут) у больных, перенесших полушарные ишемические инсульты, позволяет предотвратить развитие у них повторных нарушений мозгового кровообращения, транзиторных ишемических атак или другой сосудистой патологии (инфаркт миокарда, тромбоэмболия легочной артерии, тромбозы периферических сосудов). Кроме того, обнаружено уменьшение степени выраженности неврологической симптоматики и улучшение когнитивных функций в результате терапии препаратом Курантил ${ }^{\circledR}$ в средних дозах, что свидетельствовало об активизации восстановительных процессов в мозге. Параллельно с положительной динамикой в неврологическом статусе отмечается улучшение мозгового кровотока на 10-20\% по данным ультразвуковой допплерографии. Одновременно выявляется тенденция к снижению реактивности и нормализации функционального состояния тромбоцитов, проявляющаяся в нормализации как спонтанной, так и АДФ-индуцированной агрегации. Положительный эффект антиагрегантная терапия оказывает также на реологические свойства крови: происходит нормализация коагулогических параметров крови [11].

\section{КОМБИНИРОВАНИЕ АНТИАГРЕГАНТОВ ДЛЯ ВТОРИЧНОЙ ПРОФИЛАКТИКИ ИШЕМИЧЕСКОГО ИНСУЛЬТА}

На сегодняшний день доказано, что для многих категорий сосудистых больных высокого риска длительная антитромбоцитарная терапия предпочтительна в виде комбинации двух препаратов с различными механизмами действия. К настоящему времени наиболее убедительна доказательная база у комбинации АСК и клопидогрела - целый ряд крупных рандомизированных исследований продемонстрировал, что применение такой комбинации более эффективно, чем монотерапия АСК, клопидогрелом или каким-либо другим антиагрегантом, уменьшает риск ишемических событий при сравнимой безопасности (CURE, CREDO, CHARISMA, CLARITY-TIMI 28, COMMIT/CCS-2).

Проблема геморрагических осложнений антиагрегантной терапии - одна из самых серьезных ятрогенных проблем современной медицины.

Тем не менее есть основания полагать, что после тщательного отбора пациентов для комбинированной антиагрегантной терапии использование комбинаций с максимальными преимуществами по совокупному показателю «эффективность - безопасность» и при условии строгого контроля состояния гемостаза будет целесообразнее [8].
В исследованиях ESPS-2 (European Stroke Prevention Study, 1996) и ESPRIT (European/Australian Stroke Prevention in Reversible Ischemia Trial, 2006) были продемонстрированы высокая эффективность и безопасность добавления дипиридамола к аспирину. Такая комбинация по результатам этих исследований позволяла существенно снизить риск повторного инсульта без клинически значимого увеличения риска геморрагических осложнений. Кроме того, добавление дипиридамола дало возможность уменьшить дозу аспирина, что также положительно сказалось на безопасности терапии.

Так, в исследовании ESPS-2 использование комбинированной антитромбоцитарной терапии (ACK + дипиридамол) обусловило снижение риска повторных инсультов на 23\% по сравнению с монотерапией АСК, хотя, к сожалению, эти преимущества не отразились на уровне смертности. В исследовании ESPRIT в группе

Применение в качестве антиагреганта дипиридамола в дозе 225 мг/сут у больных, перенесших полушарные ишемические инсульты, позволяет предотвратить развитие у них повторных нарушений мозгового

кровообращения, транзиторных ишемических атак или другой сосудистой патологии

пациентов, принимавших комбинацию препаратов, частота первичной конечной точки (смерть от всех кардиоваскулярных причин, нефатальный инсульт, нефатальный инфаркт миокарда, серьезные геморрагические осложнения) была значительно ниже, чем в группе монотерапии аспирином. Особенно впечатляющими результаты ESPRIT были в отношении риска инсульта: добавление дипиридамола к стандартной антитромбоцитарной терапии аспирином обеспечило дополнительное снижение риска инсульта почти на 20\%.

Результаты ESPRIT, несмотря на некоторые ограничения исследования, позволили уже сегодня изменить рекомендации AHA/ASA, касающиеся применения комбинации ACK и дипиридамола для профилактики инсультов [16]. Назначение такой комбинации, наряду с монотерапией ACК и монотерапией клопидогрелом, показано в качестве инициальной терапии после перенесенных ТИА или некардиоэмболического ишемического инсульта, хотя при этом следует учитывать стоимость лечения, наличие сопутствующей патологии и переносимость препаратов.

\section{МЕТОДЫ ОЦЕНКИ ЭФФЕКТИВНОСТИ АНТИАГРЕГАНТНОЙ ТЕРАПИИ}

Применение антитромботических препаратов на сегодняшний день является важным звеном профилактики повторных инсультов. Профилактическая антитромботическая терапия проводится длительно и непрерывно (в течение нескольких лет) под контролем обследования агрегации тромбоцитов до назначения и через несколько 
дней после начала проведения антиагрегантной терапии. Повышение агрегационной активности тромбоцитов у пациентов с угрозой развития ишемического инсульта и эффективная медикаментозная коррекция этой патологии являются одним из критериев необходимости назначения антиагрегантов.

Успешность лечения и профилактики сосудистых заболеваний мозга препаратами с антиагрегантным механизмом во многом зависит от чувствительности, восприимчивости самих тромбоцитов к этому воздействию. Изучение изменения функциональной активности тромбоцитов при лечении антиагрегантными препаратами позволяет контролировать эффективность проводимой терапии, выявлять резистентность и сниженную реактивность к препарату, подбирать эффективное лекарственное средство и его адекватную дозу.

Существует несколько общепринятых подходов к анализу функциональной активности тромбоцитов на фоне лекарственных препаратов и оценке эффективности антиагрегантной терапии:

1) стандартная индуцированная агрегатометрия (анализ светопропускания, измерение импеданса, лазерное светорассеяние),

2) анализ функции тромбоцитов (PFA-100-анализ, VerifyNow-система),

3) биохимические тесты - VASP-фосфориляция, определение уровня тромбоксана В2 [47].

На кафедре неврологии ФДПО РНИМУ им. Н.И. Пирогова проводятся исследования по изучению тромбоцитарного звена гемостаза и реологических свойств крови у больных в восстановительном периоде инсульта. Для оценки агрегации тромбоцитов с помощью оптического агрегометра регистрируется агрегация тромбоцитов с различными индукторами, позволяющая не только выявить нарушения их функциональной активности, но и оценить эффективность терапии антиагрегантами и осуществить подбор их индивидуальной дозы.Анализируются следующие параметры, характеризующие агрегацию: степень агрегации - максимальный процент светопропускания плазмы, скорость агрегации - увеличение светопропускания за 1 мин, время агрегации - время достижения максимальной агрегации, длительность lag-фазы (латентный период). Оценка молекулярных маркеров агрегации тромбоцитов проводится путем определения фактора Виллебранда, Р- и Е-селектина методом иммуноферментного анализа.

\section{Назначение комбинации АСК и дипиридамола, наряду с монотерапией аспирином и монотерапией клопидогрелом, показано в качестве инициальной терапии после перенесенных ТИА или некардиоэмболического ишемического инсульта}

Данное исследование позволяет оценить индивидуальный ответ пациента на антитромбоцитарную терапию, обеспечить персонализированный подход к лечению каждого пациента, подобрать эффективный антитромбоцитарный препарат, снизить риск отдаленных осложнений, повторных инсультов, т. е. улучшить качество жизни и прогноз заболевания.

В будущем с развитием персонифицированной медицины для определения степени риска возникновения осложнений у пациентов, получающих антиагрегантную терапию, вероятности возникновения резистентности к антиагрегантным препаратам, снижения эффективности эндоваскулярного вмешательства, может стать необходимым не только внедрение в общую клиническую практику методов оценки индивидуального ответа пациента на антитромбоцитарную терапию, но и проведение комплексных генетических и фармакогенетических исследований, в т. ч. с использованием современных молекулярных технологий.

\section{ЛИТЕРАТУРА}

1. Алекян Б.Г., Абугов С.А., Андреев Д.А., Воробьева Н.А., Стаховская Л.В. Роль тестирования функциональной активности тромбоцитов в профилактике сердечно-сосудистых осложнений у больных, получающих антитромбоцитарную терапию. Рациональная фармакотерапия в кардиологии, 2014, 6(10): 679-687.

2. Бурячковская Л.И., Учитель И.А., Сумароков А.Б. Полифункциональность тромбоцитов, их активация и возможности ее оценки. Бюллетень НЦССХ РАМН им. Бакулева. Сердечно-сосудистые заболевания, 2007, 2: 43-50.

3. Витковский Ю.А., Голодных Ю.В., Кузник Б.И. Состояние иммунитета и лимфоцитарнотромбоцитарной адгезии при пневмонии Терапевтический архив, 2009, 81(3): 40-43.
4. Гусев Е.И., Коновалов А.Н., Скворцова В.И. Неврология. Национальное руководство. М. ГЭОТАР-Медиа, 2009, 1040 с.

5. Кузник Б.И. Клеточные и молекулярные механизмы регуляции системы гемостаза в норме и патологии. Экспресс-издательство, Чита. 2010.

6. Панченко Е.П. Атеротромбоз: механизмы развития и реально проводимая терапия. Атеротромбоз, 2008, 1: 22-27.

7. Панченко Е.П., Кропачева Е.С. Рекомендации по антитромботической терапии у больных со стабильными проявлениями атеротромбоза. Атеротромбоз, 2009, 1(2): 38-48.

8. Парфенов В.А. Факторы риска повторного ишемического инсульта и его профилактика. Неврология, нейропсихиатрия, психосоматика 2010, 3: 40-46.

9. Попова Л.В., Бокарев И.Н. Применение антиагрегантов в клинической практике. Практическая медицина, 2014, 6(82): 22-28.
10. Сергеев Д.В., Танашян М.М., Пирадов М.А. Антиагрегантная терапия при ишемическом инсульте: проблемы и перспективы. РМЖ, 2012, 31(20): 1536-1539.

11. Стаховская Л.В., Квасова О.В., Пряникова Н.А. др. Применение дипиридамола (курантила) для вторичной профилактики инсульта. Журнал неврологии и психиатрии им. С.С. Корсакова, 2000, 4: 28-31.

12. Сумароков А.Б. Новые дезагрегантные препараты. Рациональная фармакотерапия в кардиологии, 2011, 7(1): 82-88.

13. Суслина 3.А, Танашян М.М., Ионова В.Г. Ишемический инсульт: кровь, сосудистая стенка, антитромботическая терапия. М.: Медицинская книга, 2005, 248 с.

14. Суслина 3.А, Танашян М.М., Лагода О.В. Атеросклероз и ишемические нарушения мозгового кровообращения. Атеротромбоз, 2009, 2(3): 60-67. 
15. Aktas B, Utz A, Hoenig-Liedl P, Walter U, Geiger J. Dipyridamole enhances NO/cGMP-mediated vasodilator-stimulated phosphoprotein phosphorylation and signaling in human platelets: in vitro and in vivo/ex vivo studies. Stroke, 2003, 34: 764-769.

16. Adams RJ, Albers G, Alberts MJ et al. Update to the AHA/ASA Recommendations for the Prevention of Stroke in Patients With Stroke and Transient Ischemic Attack. Stroke, 2008, 39: 1647-1652.

17. Amberger A, Maczek C, Jürgens $G$, Michaelis $D$, Schett G, Trieb K, Eberl T,Jindal S, Xu Q, Wick G. Co-expression of ICAM-1, VCAM-1, ELAM-1 and Hsp60 in human arterial and venous endothelial cells in response to cytokines and oxidized low-density lipoproteins. Cell Stress Chaperones, 1997, 2(2): 94-103.

18. Barnard MR, Linden MD, Frelinger AL 3rd, Li Y, Fox ML, Furman MI, Michelson AD. Effects of platelet binding on whole blood flow cytometry assays of monocyte and neutrophil procoagulant activity. J Thromb Haemost., 2005, 3(11): 2563-70.

19. Best LC, McGuire MB, Jones PB, Holland TK, Martin TJ, Preston FE, Segal DS, Russell RG. Mode of action of dipyridamole on human platelets. Thromb Res., 1979, 16: 367-379.

20. Bhatt DL, Topol EJ. Scientific and therapeutic advances in antiplatelet therapy. Nature Reviews, 2003, 2(1): 15-28.

21. Blass KE, Block HU, Förster W, Pönicke K. Dipyridamole: a potent stimulator of prostacyclin $\left(\mathrm{PGI}_{2}\right)$ biosynthesis. Br J Pharmacol, 1980, 68: 71-73.

22. Born GV, Cross MJ. Effect of adenosine diphosphate on the concentration of platelets in circulating blood. Nature, 1963, 197 : 974-976.

23. Bressler NM, Broekman MJ, Marcus AJ. Concurrent studies of oxygen consumption and aggregation in stimulated human platelets. Blood, 1979, 53: 167-178.

24. Burch JW, Burch PT. Glutathione disulfide production during arachidonic acid oxygenation in human platelets. Prostaglandins, 1990, 39: 123-134.

25. Caro JJ, Migliaccio-Walle K, Thizon-de-Gaulle I, Coniglio AA, Kelley $\mathrm{H}$. Involvement of multiple vascular beds, CVD risk, and benefits of prevention cerebral artery stroke: PROACT investigators: Prolyse in Acute Cerebral Thromboembolism. Atherosclerosis, 1999, 9(suppl. 1): 17.

26. Cooke JP, Stamler J, Andon N, Davies PF, McKinley G, Loscalzo J. Flow stimulates endothelial cells to release a nitrovasodilator that is potentiated by reduced thiol. $\mathrm{Am} \mathrm{J}$ Physiol., 1990, 259: H804-H812.

27. Dembińska-Kieć A, Zmuda A, Wenhrynowicz O, Stachura J, Peskar BA, Gryglewski RJ. Selectin-P-mediated adherence of platelets to neutrophils is regulated by prostanoids and nitric oxide. Int J Tissue React., 1993, 15(2): 55-64.

28. Diacovo TG, Puri KD, Warnock RA, Springer TA, von Andrian UH. Platelet-mediated lymphocyte delivery to high endothelial venules. Science, 1996, 273(5272): 252-5.

29. Dresse A, Chevolet C, Delapierre D, Masset H, Weisenberger H, Bozler G, Heinzel G. Pharmacokinetics of oral dipyridamole (Persantine) and its effect on platelet adenosine uptake in man. Eur J Clin Pharmacol., 1982, 23: $229-234$.
30. Egbrink MG, Van Gestel MA, Broeders MA, Tangelder GJ, Heemskerk JM, Reneman RS, Slaa DW. Regulation of microvascular thromboembolism in vivo. Microcirculation, 2005, 12(3): 287-300.

31. Eikelbloom J, Hirsh J, Weitz J et al. Aspirinresistant thromboxane biosynthesis and the risk of myocardial infarction, stroke, or cardiovascular death in patients of high risk for cardiovascular events . Circulation, 2002, 105(14): 1650-1655.

32. Eisert WG. Dipyridamole - In Platelets Ed. Michelson A.D. Elsevier Science (USA), 2002.

33. Furman MI, Barnard MR, Krueger LA, Fox ML, Shilale EA, Lessard DM, Marchese P, Frelinger AL 3rd, Goldberg RJ, Michelson AD. Circulating monocyte-platelet aggregates are an early marker of acute myocardial infarction. J Am Coll Cardiol., 2001, 38(4): 1002-6.

34. Gamboa A, Abraham R, Diedrich A, Shibao C, Paranjape SY, Farley G, Biaggioni I. Role of adenosine and nitric oxide on the mechanisms of action of dipyridamole. Stroke, 2005, 36: 2170-2175.

35. German DC, Kredich NM, Bjornsson TD. Oral dipyridamole increases plasma adenosine levels in human beings. Clin Pharmacol Ther. 1989 45: 80-84

36. Giovanni D, Patrono, C. Platelet Activation and Atherothrombosis. N. Engl J Med., 2007, 357: 2482-94.

37. Gresele P, Arnout J, Deckmyn H, Vermylen J. Mechanism of the antiplatelet action of dipyridamole in whole blood: modulation of adenosine concentration and activity. Thromb Haemost., 1986, 55: 12-18.

38. Gresele P, Zoja C, Deckmyn H, Arnout J, Vermylen J, Verstraete M. Dipyridamole inhibits platelet aggregation in whole blood. Thromb Haemost. 1983, 50: 852-856.

39. Jagathesan R, Rosen SD, Foale RA, Camici PG, Picano E. Effects of long-term oral dipyridamole treatment on coronary microcirculatory function in patients with chronic stable angina: a substudy of the persantine in stable angina (PISA) study. J Cardiovasc Pharmacol., 2006, 48: 110-116.

40. Kawasaki K, Smith RS Jr, Hsieh CM, Sun J, Chao J, Liao JK. Activation of the phosphatidylinositol 3-kinase/protein kinase Akt pathway mediates nitric oxide-induced endothelial cell migration and angiogenesis. Mol Cell Biol, 2003, 23: 5726 5737.

41. Koda M, Banno Y, Naganawa T. Effect of neutrophil adhesion on the size of aggregates formed by agonist-activated platelets. Platelets, 2005, 16(8): 482-91.

42. Leppo JA, O’Brien J, Rothendler JA, Getchell JD, Lee VW. Dipyridamole - thallium-201 scintigraphy in the prediction of future cardiac events after acute myocardial infarction. N Engl J Med. 1984, 310: 1014-1018.

43. Michelson AD, Barnard MR, Krueger LA, Valeri CR, Furman MI. Circulating monocyte-platelet aggregates are a more sensitive marker of in vivo platelet activation than platelet surface P-selectin: studies in baboons, human coronary intervention, and human acute myocardial infarction. Circulation, 2001, 104: 1533-1537.

44. Mills DC, Smith JB. The influence on platelet aggregation of drugs that affect the accumulation of adenosine 3 ':5'-cyclic monophosphate in platelets. Biochem J, 1971 121: 185-196.
45. Myers DD, Hawley AE, Farris DM, Wrobleski SK, Thanaporn P, Schaub RG, WagnerDD, Kumar A, Wakefield TW. P-selectin and leukocyte microparticles are associated with venous thrombogenesis. J Vasc Surg, 2003 Nov, 38(5): 1075-89.

46. Nakamura T, Uchiyama S, Yamazaki M, Iwata M. Effects of dipiridamole and aspirin on shearinduced platelet aggregation in whole blood and platelet-rich plasma. Cerebrovasc. Dis. 2002, 14(3-4): 234-238.

47. Oestreich JH, Smyth S, Campbell Ch. Platelet function analysis: at the edge of meaning. Thromb Haemost, 2009, 101(2): 217-219.

48. Patsouros N, Laboux P, Chatelain B, Chatelain C. Aspirin resistanse as possible risk factor in stroke occurrence. Cerebrovascular Diseases, 2003, 16(Suppl. 4): 82-83.

49. Rinder HM, Tracey JL, Rinder CS, Leitenberg D, Smith BR. Neutrophil but not monocyte activation inhibits P-selectin-mediated platelet adhesion. Thromb Haemost, 1994, 72(5): 750-6.

50. Santoso S, Sachs UJ, Kroll H, Linder M, Ruf A, Preissner KT, Chavakis T. The junctional adhesion molecule 3 (JAM-3) on human platelets is a counterreceptor for the leukocyte integrin Mac-1. J Exp Med, 2002, 196(5): 679-91.

51. Schmidtke DW, Diamond SL. Direct observation of membrane tethers formed during neutrophil attachment to platelets or P-selectin under physiological flow. J Cell Biol, 2000, 149(3): 719-30.

52. Schoeffter P, Lugnier C, Demesy-Waeldele F, Stoclet JC. Role of cyclic AMP- and cyclic GMPphosphodiesterases in the control of cyclic nucleotide levels and smooth muscle tone in rat isolated aorta. A study with selective inhibitors. Biochem Pharmacol, 1987, 36: 39653972.

53. Schwertz H, Tolley ND, Foulks JM, Denis MM, Risenmay BW, Buerke M, Tilley RE, Rondina MT, Harris EM, Kraiss LW, Mackman N, Zimmerman GA, Weyrich AS. Signal-dependent splicing of tissue factor pre-mRNA modulates the thrombogenicity of human platelets. J Exp Med, 2006, 203(11): 2433-40.

54. Shultz PJ, Raij L. Endogenously synthesized nitric oxide prevents endotoxin-induced glomerular thrombosis. J Clin Invest, 1992, 90: 1718-1725.

55. Smith JB, Mills DC. Inhibition of adenosine 3',5'-cyclic monophosphate phosphodiesterase. Biochem J, 1970, 120: 20P.

56. Smyth SS, Joneckis CC, Parise LV. Regulation of vascular integrins. Blood, 1993, 81(11): 2827-43.

57. Wang JM, Wang Y, Huang JY, Yang Z, Chen L, Wang LC, Tang AL, Lou ZF, Tao J. C-Reactive protein-induced endothelial microparticle generation in HUVECs is related to $\mathrm{BH} 4$ dependent NO formation. J Vasc Res, 2007, 44(3): 241-8

58. Yang J, Furie BC, Furie B. The biology of P-selectin glycoprotein ligand-1: its role as a selectin counterreceptor in leukocyte-endothelial and leukocyte-platelet interaction. Thromb Haemost, 1999 Jan, 81(1): 1-7.

59. Yang Z, Ming XF. Recent advances in understanding endothelial dysfunction in atherosclerosis. Clin Med Res, 2006, 4(1): 53-65.

60. http:.atvb.ahajournals.org/content/28/3/s39.full - ref-13.

61. http:.atvb.ahajournals.org/content/28/3/s39.full - ref-42. 